\title{
An Unexpected Dependence of Cortical Depth in Shaping Neural Responsiveness and Selectivity in Mouse Visual Cortex
}

\author{
Philip O'Herron, ${ }^{1,2}$ Manuel Levy, ${ }^{1,3}$ @John J. Woodward, ${ }^{1}$ and $\odot$ Prakash Kara ${ }^{1,4}$
}

https://doi.org/10.1523/ENEURO.0497-19.2020

${ }^{1}$ Department of Neuroscience, Medical University of South Carolina, Charleston, SC 29425, ${ }^{2}$ Department of Physiology, Augusta University, Augusta, GA 30912, ${ }^{3}$ Department of Neurobiology, Duke University, Durham, NC 27710 , and ${ }^{4}$ Department of Neuroscience, University of Minnesota, Minneapolis, MN 55455

\begin{abstract}
Two-photon imaging studies in mouse primary visual cortex (V1) consistently report that around half of the neurons respond to oriented grating stimuli. However, in cats and primates, nearly all neurons respond to such stimuli. Here we show that mouse V1 responsiveness and selectivity strongly depends on neuronal depth. Moving from superficial layer 2 down to layer 4, the percentage of visually responsive neurons nearly doubled, ultimately reaching levels similar to what is seen in other species. Over this span, the amplitude of neuronal responses also doubled. Moreover, stimulus selectivity was also modulated, not only with depth but also with response amplitude. Specifically, we found that orientation and direction selectivity were greater in stronger responding neurons, but orientation selectivity decreased with depth whereas direction selectivity increased. Importantly, these depth-dependent trends were found not just between layer 2/3 and layer 4 but at different depths within layer 2/3 itself. Thus, neuronal depth is an important factor to consider when pooling neurons for population analyses. Furthermore, the inability to drive the majority of cells in superficial layer $2 / 3$ of mouse V1 with grating stimuli indicates that there may be fundamental differences in the micro-circuitry and role of $\mathrm{V} 1$ between rodents and other mammals.
\end{abstract}

Key words: calcium; laminae; multi-photon; neocortex; selectivity; two-photon

\section{Significance Statement}

Studies frequently pool responses of neurons from different cortical depths in population analyses. Here, we show that population neuronal response characteristics in mouse primary visual cortex (V1) vary dramatically across depth planes separated by just $50 \mu \mathrm{m}$. We also demonstrate that the stimulus selectivity of neuronal responses varies with both cortical depth and the response amplitude of neurons. These findings highlight the importance of considering cell depth and response amplitude as important factors contributing to the overall characteristics of neurons in sensory cortex.

\section{Introduction}

With the emergence of two-photon imaging as a tool for systems neuroscience over the past 15 years, there has been an enormous increase in the use of the mouse as a model system to study cortical neuronal physiology. Mice are easily genetically modified to label specific populations

Received November 21, 2019; accepted January 31, 2020; First published February 12, 2020.

The authors declare no competing financial interests. of neurons with fluorescent indicators and opsins, allowing the study of cell type-specific circuitry (Luo et al., 2008; Scanziani and Häusser, 2009; Zhao et al., 2011; Adesnik et al., 2012; Lee et al., 2012). Additionally, because they are much smaller than cats and primates, brain pulsations due to respiration and heartrate are easier to control. Although 
these features have made the mouse a valuable model in many respects, some differences have been noted between the visual system of mice and that of cats and primates. The functional organization of neurons into orientation maps that is prevalent across many species is absent in rodents (Ohki et al., 2005; but see Fahey et al., 2019). Additionally, the proportion of pyramidal neuronal synapses onto inhibitory neurons was found to be much greater in rodents than in cats or monkeys (Bock et al., 2011; Bopp et al., 2014).

A further difference that has become apparent in the literature is the percentage of responsive neurons in the cortex. An early electrophysiological study reported that most neurons (87\%) in mouse V1 were responsive to grating stimuli (Niell and Stryker, 2008). However, electrophysiological recordings are blind to "silent" neurons which do not show spontaneous or evoked activity during the recordings, and thus the true percentage of all neurons that are responsive is difficult to measure. Subsequent studies using two-photon calcium imaging, which can record activity levels from all neurons in a region, have consistently reported that around half of the neurons in mouse V1 respond significantly to oriented grating stimuli (MrsicFlogel et al., 2007; Sohya et al., 2007; Kerlin et al., 2010; Smith and Häusser, 2010; Bonin et al., 2011; Ebina et al., 2014; Ayzenshtat et al., 2016; Palagina et al., 2017). However, the few two-photon calcium imaging studies done in V1 in primates and cats indicate a much higher percentage of responsive neurons to grating stimuli - typically $>90 \%$ of the neurons are responding (Kara and Boyd, 2009; Nauhaus et al., 2012; Shen et al., 2012; Ikezoe et al., 2013; Li et al., 2017).

In addition to these differences in responsiveness and functional connectivity, the mouse neocortex is also much thinner than that of cats and primates. As a result, neurons from layers 1 through 4 can be easily accessed with conventional two-photon imaging techniques in the mouse visual cortex, whereas in cats and primates twophoton imaging is limited to the upper portion of layer $2 / 3$. Although the ability to image more of the neocortex in the mouse can certainly be an advantage, it raises important considerations about how populations of neural activity should be analyzed and the functional differences of these populations across species. Layers of the neocortex have different anatomical and functional characteristics and play different roles in the basic circuitry of information processing (Douglas and Martin, 1991; D'Souza and Burkhalter, 2017). Yet, most imaging studies in mouse $\mathrm{V} 1$ pool neuronal responses without regard for recording depth. Even when layer is taken into consideration, (Kondo and Ohki, 2016; Sun et al., 2016;

This work was supported by NIH Grants R01MH111447 and R21AA022168. Acknowledgements: We thank Adrien Schramm for assistance with the glutamate control experiments.

Correspondence should be addressed to Prakash Kara at pkara@umn.edu. https://doi.org/10.1523/ENEURO.0497-19.2020 Copyright @ 2020 O'Herron et al.

This is an open-access article distributed under the terms of the Creative Commons Attribution 4.0 International license, which permits unrestricted use, distribution and reproduction in any medium provided that the original work is properly attributed.
Yildirim et al., 2019) it is very rare to distinguish neurons by depth within a layer.

In the present study, we sought to determine how the response properties of neurons in mouse V1 depend on cortical depth. We show that although in superficial layer $2 / 3$ only around half of the neurons are responding to grating stimuli, deep in layer $2 / 3$ and in layer 4 , nearly all the neurons are responsive, similar to what is seen in cats and primates. We demonstrate that the amplitude and the selectivity of neuronal responses to drifting grating stimuli depend on imaging depth - not only across laminae but even within layer $2 / 3$ itself. Neuronal selectivity to orientation and direction across the population changes little with cortical depth, in agreement with previous studies (Niell and Stryker, 2008; Ma et al., 2010; Van den Bergh et al., 2010; Durand et al., 2016; Kondo and Ohki, 2016; Sun et al., 2016; Yildirim et al., 2019). However, this apparent homogeneity masks strong differences in orientation and direction selectivity when neurons are separated according to both depth and response strength. We discuss the implications of our findings with respect to the differences in visual processing between mice, cats and primates.

\section{Materials and Methods}

Animals and surgery. All surgical and experimental procedures were approved by the Institutional Animal Care and Use Committee at Medical University of South Carolina (MUSC). All experiments were performed at MUSC. C57Bl/6J mice ( $n=7$ male, postnatal day 90-111) were initially anaesthetized with a bolus infusion of fentanyl citrate (0.04-0.05 mg kg ${ }^{-1}$ ), midazolam (4-5 mg kg ${ }^{-1}$ ), and dexmedetomidine $\left(0.20-0.25 \mathrm{mg} \mathrm{kg}^{-1}\right)$. During twophoton imaging, continuous intraperitoneal infusion with a lower concentration mixture (fentanyl citrate: 0.002$0.003 \mathrm{mg} \mathrm{kg}^{-1} \mathrm{~h}^{-1}$, midazolam: $0.2-0.3 \mathrm{mg} \mathrm{kg}^{-1} \mathrm{~h}^{-1}$, and dexmedetomidine: $0.010-0.15 \mathrm{mg} \mathrm{kg}^{-1} \mathrm{~h}^{-1}$ ) was administered using a catheter connected to a syringe pump. The heart and respiration rates of the animals were continually monitored throughout the surgeries and imaging. Craniotomies (2-3 mm) were opened over the primary visual cortex (V1) centered $\sim 2.5 \mathrm{~mm}$ lateral to the lamda suture and 1-1.5 $\mathrm{mm}$ anterior to the transverse sinus. A pipette containing a solution with Oregon Green 488 Bapta-1 AM (OGB-1 AM) and a red dye (Alexa Fluor 633 or Alexa Fluor 594) was inserted into the craniotomy and the dye was injected with pressure puffs under continuous visual guidance using two-photon microscopy (O'Herron et al., 2012). Pipette tips were positioned between 160 and $265 \mu \mathrm{m}$ deep for the injections (mean depth $193 \mu \mathrm{m}$ across seven animals). After waiting $1 \mathrm{~h}$, the dura was removed and the craniotomies were sealed with agarose (1.5-2\% dissolved in artificial cerebrospinal fluid) and a 5-mm glass coverslip.

Fluorescence was monitored with a custom-built microscope (Prairie Technologies) coupled with a Mai Tai (Newport Spectra-Physics) mode-locked Ti:sapphire laser (810 or $920 \mathrm{~nm}$ ) with DeepSee dispersion compensation. Excitation light was focused by a $40 \times($ NA 0.8 , Olympus) water immersion objective. Full frame imaging of $\sim 300-\mu \mathrm{m}$ square windows was obtained at $\sim 0.8 \mathrm{~Hz}$. 
Drifting square-wave grating stimuli were presented to the contralateral eye on a 17 -inch LCD monitor. The gratings were presented at $100 \%$ contrast, $30 \mathrm{~cd} \mathrm{~m}^{-2}$ mean luminance, $1.5-\mathrm{Hz}$ temporal frequency, and $0.033-0.063$ cycles $/{ }^{\circ}$. Stimuli were optimized for retinotopic position and spatial frequency preference right at the layer $1 /$ layer 2 border (typically around $120-\mu \mathrm{m}$ depth). Our injection site usually yielded receptive fields close to eye level $\left(0^{\circ}\right.$ elevation) and roughly perpendicular to the eye (azimuth around $50-70^{\circ}$. At each of our depth planes, drifting gratings were presented at 16 directions of motion in $22.5^{\circ}$ steps (except 1 of 35 runs which used 8 directions in $45^{\circ}$ steps) for $6.5 \mathrm{~s}$ with $13 \mathrm{~s}$ of blank before each stimulus. Each condition was repeated at least 8 times except for two runs with only five repetitions due to the removal of later repetitions on account of large movements.

Images were analyzed in MATLAB (MathWorks) and ImageJ (National Institutes of Health). Data with significant movements (several micrometers) in XY or Z were excluded. Data with small drift movements were realigned by maximizing the correlation between frames. Cell masks were automatically created based on morphologic features and then subsequently refined by hand. Astrocytes were removed from the data based on morphologic criteria (Gandhi et al., 2008; Runyan et al., 2010; Van Hooser et al., 2012) and in 2 animals we verified this method by labeling astrocytes with Sulforhodamine 101. Fluorescence time courses for each cell were computed by averaging over the pixels in each mask. The time courses were corrected for neuropil contamination similar to Kerlin et al. (2010). First, out of focus neuropil contamination was estimated from the fluorescence in small vessels $(<15 \mu \mathrm{m})$. The fluorescence from hand-drawn vessel masks was divided by the fluorescence of the surrounding neuropil to obtain an estimate of the fraction $C$ of the response that is attributable to out of focus contamination. Then the fluorescence time course for soma masks were corrected by subtracting this fraction of the surrounding neuropil fluorescence. So:

$$
\mathrm{F}_{\text {cell_true }}(\mathrm{t})=\mathrm{F}_{\text {cell_measured }}(\mathrm{t})-\mathrm{C} \times \mathrm{F}_{\text {neuropil }}(\mathrm{t}),
$$

where $t$ is time and $F$ is fluorescence. Values for $C$ were between 0.35 and 0.72 (median $=0.56$ ). Neuropil masks were created by expanding a spherical shell $15 \mu \mathrm{m}$ beyond the soma masks. The inner $3 \mu \mathrm{m}$ were excluded as a buffer zone around each neuron. Pixels were also excluded from the neuropil masks if they belonged to other soma masks and their $3 \mu \mathrm{m}$ shells, blood vessels, nonneuronal cell bodies (such as astrocytes), or neuronal somas that were too out of focus to be included in the population. The radius of the neuropil mask was expanded, if necessary, until the neuropil area was greater than 10 times the soma area. The median radius of the neuropil masks was $14 \mu \mathrm{m}$ and the range was $12-32 \mu \mathrm{m}$.

The time courses for each neuron were then normalized by a sliding baseline of the mean fluorescence of the last four frames of each blank interval. The responses to each condition $(\Delta F / F)$ were computed as $\left(F_{1}-F_{0}\right) / F_{0}$ where $F_{1}$ was the average fluorescence across all 5 stimulus frames and $F_{0}$ was the average of the last four frames of each blank interval. Neurons were defined as responsive using ANOVA across the 16 directions and the blank intervals $(p<0.01)$. Because different studies have used different criteria for responsiveness, we did two additional analyses using different criteria: (1) with $p$ set to 0.001 , and (2) where responsiveness was defined as average $\Delta F / F>5 \%$ for at least one stimulus direction. The data showed the same depth-dependent trends in both cases (Table 1). The response amplitude was computed for all responsive neurons.

The Orientation Selectivity Index (OSI) was defined as:

$$
O S I=a b s\left(\frac{\sum_{k} r_{k} e^{i 2 \theta_{k}}}{\sum_{k} r_{k}}\right),
$$

where $\theta_{k}$ is the orientation of each stimulus and $r_{k}$ is the mean response across trials to that stimulus (Swindale, 1998; Ringach et al., 2002). Note that OSI $=1$ - circular variance. The Orientation Modulation Index (OMI) was defined as:

$$
\mathrm{OMI}=\left(R_{\text {pref }}-R_{\text {ortho }}\right) /\left(R_{\text {pref }}+R_{\text {ortho }}\right),
$$

where $R_{\text {pref }}$ is the response to the stimulus direction that evoked the strongest response and $R_{\text {ortho }}$ is the average of the responses to the two orthogonal stimuli. Note that this metric is sometimes referred to as the OSI while what we term the OSI is sometimes referred to as the global OSI (gOSI; Kondo and Ohki, 2016; Sun et al., 2016; Yildirim et al., 2019). The OSI and OMI were computed on all responsive neurons.

To analyze the tuning width of the neurons, we first screened the population for selective neurons. Neurons were tested to see if any of the stimulus conditions evoked a significantly different response from any other (ANOVA, $p<0.01$ ). If so, each neuron's responses were then fit with a least-squares method to a Von Mises function:

$$
f(\theta)=A \cdot e^{\kappa(\cos (2(\theta-\varphi))-1)}+B,
$$

where $\theta$ is the orientation values, $A$ corresponds to the peak amplitude, $\varphi$ to the preferred orientation, $\kappa$ is a width parameter, and $B$ reflects the baseline response (Swindale, 1998). If the peak of the curve was not at least twice the trough (approximating the preferred response being at least twice the magnitude of the least preferred), neurons were excluded. Additionally, the $\mathrm{R}^{2}$ for the fit had to be at least 0.5 for inclusion in the selective population. For neurons that passed these criteria, we computed a population average response for each animal and depth plane. Each neuron's responses were normalized to the peak response of that neuron and the preferred orientation was set to $0^{\circ}$ before averaging.

Bandwidth was computed based on Swindale (1998):

$$
B W=\cos ^{-1}\{(\ln 0.5+\kappa) / \kappa\} .
$$

This metric gives the full bandwidth of the curve in degrees and is independent of the baseline level.

To compute direction selectivity, we fit a double von Mises curve to the population average responses in each animal and depth plane: 


$$
f(\theta)=A_{1} \cdot e^{\kappa\left(\cos \left(2\left(\theta-\varphi_{1}\right)\right)-1\right)}+A_{2} \cdot e^{\kappa\left(\cos \left(2\left(\theta-\varphi_{2}\right)\right)-1\right)}+B,
$$

where $A_{1}$ was the amplitude at the preferred direction, $A_{2}$ was the amplitude of the second peak, and $\varphi_{2}$ was constrained to be $\varphi_{1}+180^{\circ}$. The other parameters are as above.

The Direction Modulation Index (DMI) was defined as:

$$
D M I=\left(A_{1}-A_{2}\right) /\left(A_{1}+A_{2}\right),
$$

Stimulus-evoked "shadowing" from large surface vessel dilation can cause dimming of fluorescence from neurons during stimulus presentation windows. When neurons are not responding or responding weakly, this shadowing may lead to negative $\Delta \mathrm{F} / \mathrm{F}$ values from these neurons (Shen et al., 2012). This is because surface arteries in visual cortex show strong dilations to all stimulus conditions (O'Herron et al., 2016) while neurons may only fluoresce strongly to a few stimulus conditions. Including these negative responses in the computation of the OSI and OMI can lead to aberrant values. Therefore, if neurons showed decreased fluorescence to stimuli, we shifted all responses up by the most negative value (setting that value to zero). For consistency, all selectivity measures were performed on this shifted data. To ensure that this correction was not a confound, we performed two control analyses. First, we computed the tuning width without this correction and saw similar results (Table 1, uncorrected data). Second, we rectified all the negative responses to zero without adjusting the positive responses. We then checked all of the selectivity metrics and again found that, despite small differences in the values of some metrics, they all showed the same depth-dependent trends (data not shown).

\section{Results}

We imaged calcium responses in the mouse visual cortex at depth planes ranging from $150 \mu \mathrm{m}$ to $350 \mu \mathrm{m}$ below the surface in 50- $\mu \mathrm{m}$ increments. We used the synthetic calcium indicator OGB-1 AM. When injected by visualized guidance under two-photon microscopy (see Materials and Methods; Kara and Boyd, 2009; O'Herron et al., 2012; Shen et al., 2012), this dye uniformly labels all cells within a small region of tissue $(300-400 \mu \mathrm{m}$ around the injection site) regardless of lamina. This labeling strategy ensures that the responsiveness of all the neurons in each imaged plane can be determined (see Discussion). In our study, the density of neurons in mouse visual cortex was similar across depth planes except for an increase in the deepest plane (Fig. 1; Table 1). Based on the cell count and on the delineation of layers in the literature ( $\mathrm{Ji}$ et al., 2015; Durand et al., 2016; Kondo and Ohki, 2016; Sun et al., 2016), the three superficial depths (150, 200, and $250 \mu \mathrm{m}$ ) are within layer $2 / 3$, the $350 \mu \mathrm{m}$ depth is within layer 4, and the $300 \mu \mathrm{m}$ depth is near the border of layers 3 and 4 . Across all depth planes we found that many neurons responded robustly to drifting grating stimuli (Fig. 1; Extended Data Fig. 1-1). However, the proportion of responsive neurons (ANOVA across all stimuli plus blank presentations; see Materials and Methods) increased dramatically with depth (Figs. 1, 2A; Extended Data Fig. 1-1). The average percentage of responsive neurons in superficial layer $2 / 3$ was $\sim 50 \%$, similar to what has been reported in the literature (Mrsic-Flogel et al., 2007; Sohya et al., 2007; Kerlin et al., 2010; Smith and Häusser, 2010; Bonin et al., 2011; Ebina et al., 2014; Ayzenshtat et al., 2016; Palagina et al., 2017). Deeper in layer $2 / 3$ this ratio rose to $>80 \%$, and in layer 4 around $90 \%$ of neurons were responding. This increase in responsiveness with depth was highly significant $\left(R^{2}=0.70\right.$, $p<10^{-9}$, linear regression, $n=35$ imaged regions in seven mice; Fig. 2A; Table 1) and was observed in every animal tested (Fig. 2A; Table 1; $R^{2}>0.79$ and $p<0.04$ for all animals, $n=5$ regions per animal). Nearly all neurons $(95 \%)$ within layer $2 / 3$ responded to pharmacological stimuli (glutamate puffs, see Extended Data Fig. 1-2; Discussion), thus excluding the possibility that non-visually responsive neurons were unhealthy. Out of a total population of 6720 neurons imaged across all animals and depths, 5020 were significantly responsive to visual stimuli and were analyzed further.

The depth dependence of neuronal responsivity to visual stimuli was observed not only in the proportion of responsive neurons but also in their maximum response amplitude. Responses to the preferred stimulus direction nearly doubled from $15.5 \pm 2.2 \%$ (mean $\Delta \mathrm{F} / \mathrm{F} \pm \mathrm{SD}$ across runs) in superficial layer $2 / 3$ to $28.9 \pm 4.7 \%$ in layer 4 (Fig. 2B,C). This depth dependence of preferred response amplitude was highly significant $\left(R^{2}=0.66\right.$, $p<10^{-8}, n=35$ regions neurons from seven animals; Fig. 2B; Table 1).

Previous studies reported that orientation selectivity remains approximately constant across cortical depth (Niell and Stryker, 2008; Ma et al., 2010; Van den Bergh et al., 2010; Durand et al., 2016; Kondo and Ohki, 2016; Sun et al., 2016; Yildirim et al., 2019). However, as we showed above, neuronal responsiveness changes with cortical depth. The effects of these two factors (response strength and cortical depth) on orientation selectivity have not been considered separately in previous studies. We computed the OSI (see Materials and Methods), a fit-free index that quantifies the spread of neuronal responses across orientations (OSI $=1$ when a neuron responds only to one orientation). When the OSI was pooled across all neurons at each depth plane, we found that orientation selectivity very slightly decreased with depth, going from $0.36 \pm 0.05$ in superficial layer $2 / 3$ to $0.32 \pm 0.02$ in layer 4 $\left(R^{2}=0.12, p=0.04, n=35\right.$ regions neurons from seven animals; Fig. $3 A$; Table 1). However, a more detailed analysis of the effects of depth and responsivity on OSI showed these two factors affected orientation selectivity in different ways. When neurons were divided into three equal-sized groups based on their preferred response amplitude (weak responders, $\Delta \mathrm{F} / \mathrm{F}<15 \%, n=1672$; middle responders $15 \% \leq \Delta \mathrm{F} / \mathrm{F} \leq 24 \%, n=1673$; strong responders, $\Delta F / F>24 \%, n=1675)$, for each group, neurons were much less orientation selective deeper in the cortex (Fig. 3B). The change in OSI with depth was particularly pronounced for strong responders $\left(R^{2}=0.69, p<10^{-9}\right)$ and middle responders $\left(R^{2}=0.67, p<10^{-8}\right)$ compared 

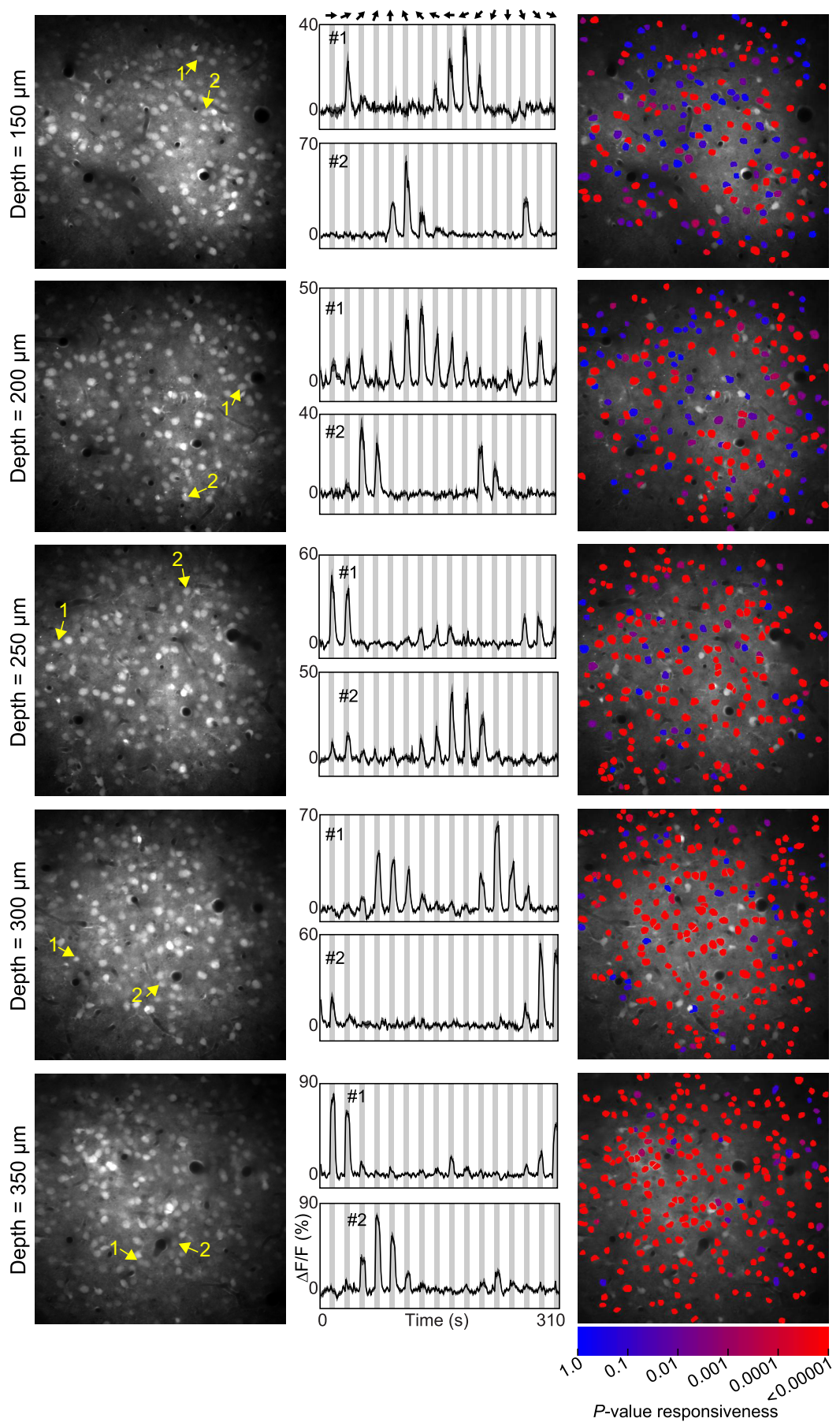

Figure 1. Increased neural responsiveness with cortical depth in mouse V1. Left, Anatomical images of five different depth planes from one mouse. Center, Time courses of responses from two example cells from each depth plane as indicated by yellow numbers/arrows in left column. Right, Neuronal cell masks are color coded by the $p$ value from the ANOVA for responsiveness. With increasing depth there are more cell masks colored in redder hues, indicating increased responsiveness. See Extended Data Figure 1-1 for pixel-based direction maps across cortical depth. Also see Extended Data Figure 1-2 for cortical responses to pharmacological stimuli.

with weak responders $\left(R^{2}=0.41, p<10^{-4}\right)$. Additionally, independent of depth, strong responders were more orientation selective than middle responders (one-way ANOVA with response group as factor, Tukey's post hoc test $p<10^{-7}$ ) which, in turn, were more selective than weak responders $\left(p<10^{-9}\right)$. Thus, orientation selectivity is affected by two competing trends. On the one hand, for a given level of responsiveness, orientation selectivity decreases when depth increases. On the other hand, at a given depth, orientation selectivity increases when neuronal responses increase. The two trends cancel each other out because depth covaries with neuronal responsivity 
A

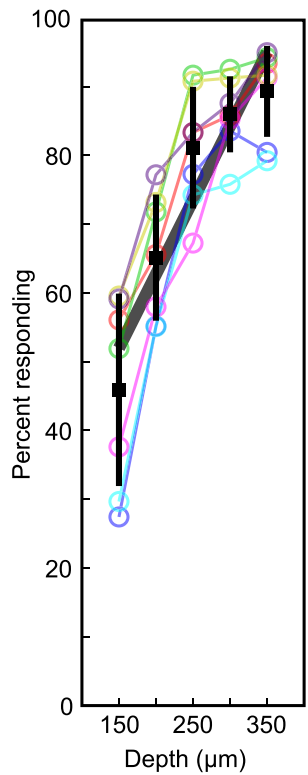

B

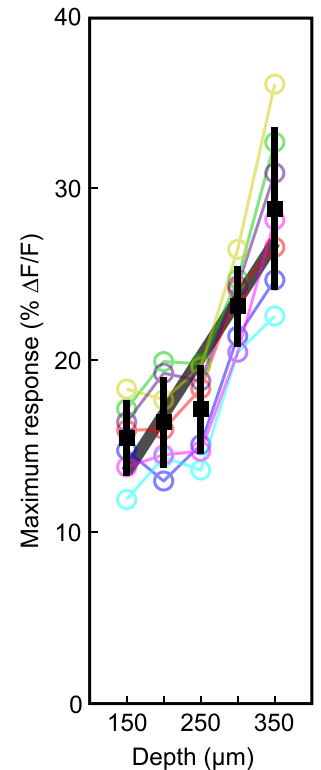

C

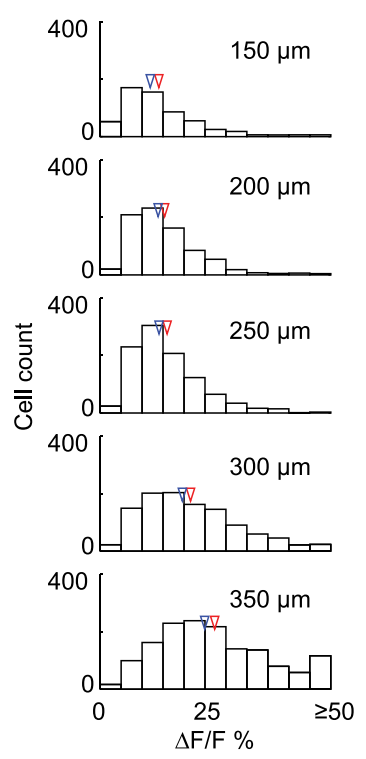

Figure 2. Population summary of cortical depth dependence on neural responsiveness and response amplitude. $\boldsymbol{A}$, Percentage of responding neurons as a function of imaging depth. In this and subsequent panels/figures, colored lines and circles correspond to individual mice and black squares correspond to the population average at each depth. Error bars indicate SD. The thick gray line is the linear fit to the individual runs. $\boldsymbol{B}$. Change in response amplitude with depth. $\boldsymbol{C}$, Histogram of the distribution of response amplitude across the neuronal population at each depth plane. Blue arrows correspond to the median and red arrows to the mean.

(Extended Data Fig. 3-1), resulting in approximately constant OSI across depth.

In order to understand in more detail how depth affects orientation tuning, we fit the responses with a von Mises curve (Swindale, 1998). First, responsive neurons were screened for orientation selectivity (see Materials and
Methods) which excluded $\sim 24 \%$ of the responsive neurons $(1187 / 5020)$. The responses of the remaining 3833 orientation selective neurons were normalized and aligned relative to each neuron's preferred stimulus orientation, and a von Mises curve was fit to the population average of each animal at each depth (Fig. 4A). We found that the two
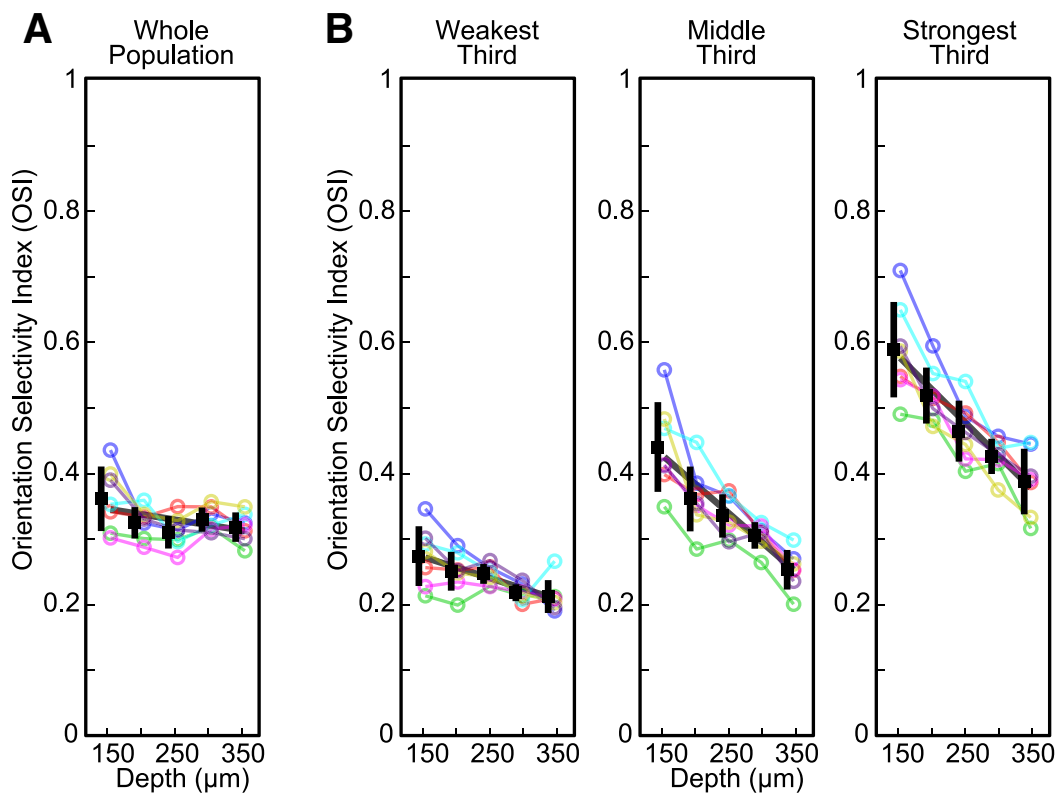

Figure 3. Cortical depth dependence of the OSI. A, Average of OSI values for each mouse and imaging depth. $\boldsymbol{B}$, Average after dividing neurons into three groups based on response amplitude. Conventions as in previous figure. Also see Extended Data Figure 3-1 for the OSI of every responsive neuron in the population grouped by response amplitude and depth. 

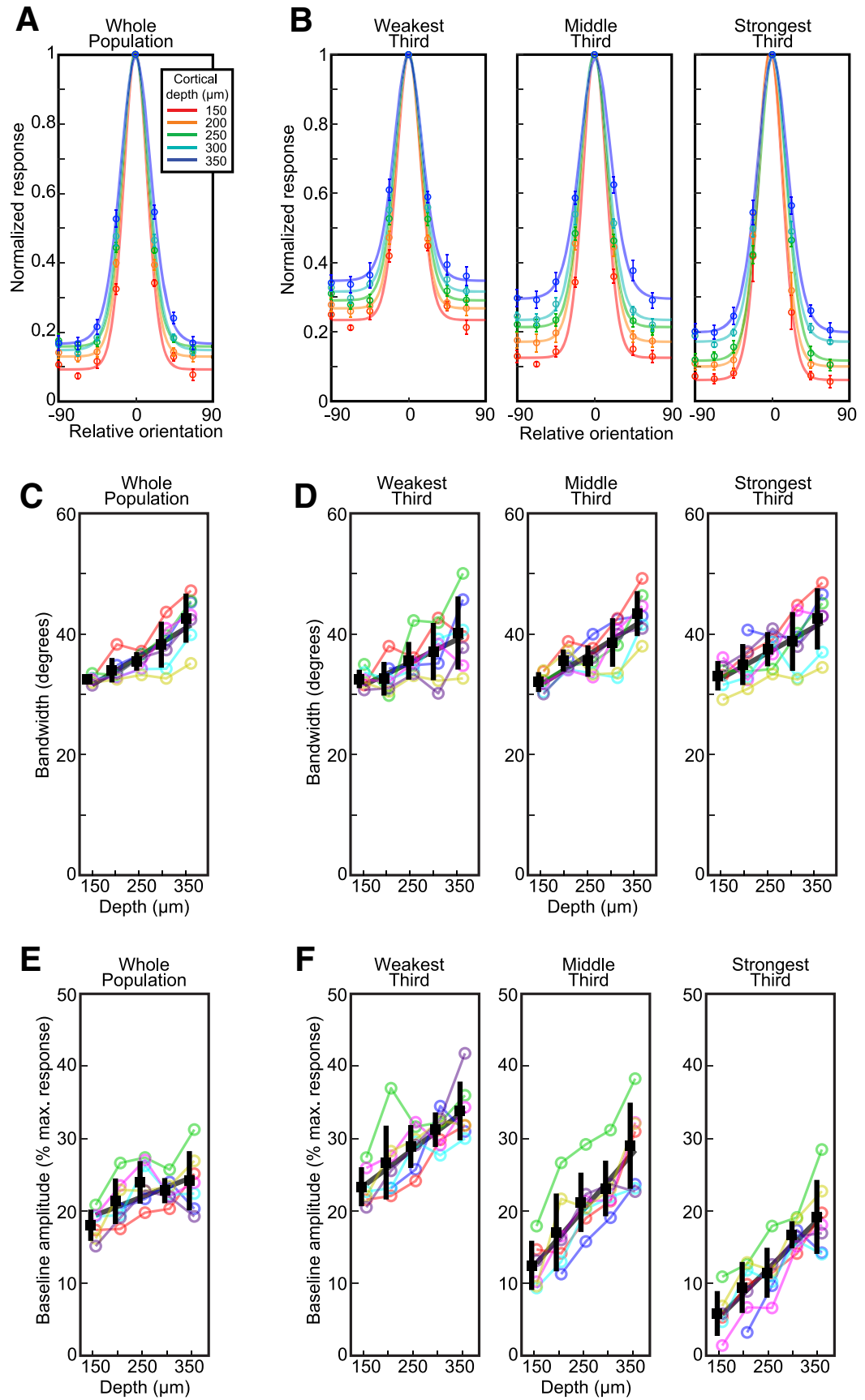

Figure 4. Cortical depth dependence of orientation tuning width. $\boldsymbol{A}$, At each imaging depth, the population average response is shown and fit with a tuning curve. Averages were computed for each run (five depth planes, seven animals) after aligning preferred orientations and normalizing to the maximum response for each neuron. The responses at each depth plane were then averaged across animals to obtain the population average (circles) and SD (error bars). $\boldsymbol{B}$, Population averages grouped by response amplitude. $\boldsymbol{C}$, The bandwidth of the tuning curves for each animal/depth plane (colored circles) and the population average (black squares) and SD (black bars). The gray line is the linear fit to the individual animal data. $\boldsymbol{D}$, Similar to panel $\boldsymbol{C}$ but for neurons grouped by response amplitude. $\boldsymbol{E}, \boldsymbol{F}$, Similar to $\boldsymbol{C}, \boldsymbol{D}$ but for the baseline amplitude of the tuning curves.

parameters in these fitted curves, the bandwidth (Eqs. 4, 5) and the baseline (parameter B in Eq. 4), both increased from superficial layer $2 / 3$ to layer 4 (bandwidth: $32.4^{\circ}$ in superficial layer $2,42.6^{\circ}$ in layer $4, R^{2}=0.62, p<10^{-7}$; baseline: $18 \%$ of peak response in layer $2,24 \%$ in layer $4, R^{2}=$ $0.28, p<0.005$; Fig. 4A,C,E; Table 1). Note that parameter $B$ in Equation 4 does not represent spontaneous activity but is the weakest of all visually-evoked responses to the various oriented stimuli presented.

We separately analyzed the effects of response strength and depth on orientation tuning curves by dividing the selective neurons into three equal groups based on response amplitude (weak responders, $\Delta \mathrm{F} / \mathrm{F}<16 \%$, $n=1277$ neurons; middle responders $16 \% \leq \Delta \mathrm{F} / \mathrm{F} \leq$ 
$26 \%, n=1277$ neurons; strong responders, $\Delta \mathrm{F} / \mathrm{F}>26 \%$, $n=1279$ neurons). We observed the same trends as for the OSI: namely that stronger responders tended to be more orientation selective than weak responders, and that their tuning curves varied more with depth (Fig. 4B). The fits showed that although bandwidth increased with depth in each response amplitude group, it did not vary across response groups (depth factor $p<10^{-10}$; response group factor $p=0.12$; two-way ANOVA; Fig. 4B,D; Table 1). In contrast, baseline depended strongly on both depth and response strength: deep neurons and weakly responding neurons showed high baseline responses at all orientations, whereas neurons that were located more superficially and strong responders had lower baselines and were consequently more orientation selective (depth factor $p<10^{-16}$; response group factor $p<10^{-27}$; Fig. $4 B, F ;$ Table 1).

Another metric often used to quantify orientation selectivity is the difference in response between the preferred and orthogonal stimuli divided by their sum (but see Mazurek et al., 2014 for its limitations). We computed this OMI (see Materials and Methods) for each of the responsive neurons. The results were similar to what we found for the OSI except that the OMI values were consistently higher than the OSI values. The whole population showed essentially no change in selectivity with depth $\left(R^{2}=0.05\right.$, $p=0.18$, regression; ANOVA, $p=0.05$; Fig. $5 A$; Table 1). However, the separate groups all showed significant decreases in OMI with depth (Fig. 5B; Table 1) and the stronger responding neurons had greater OMI values (one-way ANOVA with response group as factor, Tukey's post hoc test $p<10^{-9}$ for both strongest vs middle and middle vs weakest; Fig. 5B).
Finally, the data were analyzed to determine the effect of depth on direction selectivity. Surprisingly, we found that direction selectivity increased with cortical depth, and thus followed a pattern opposite to orientation selectivity. We computed population tuning curves for each depth as above but without averaging across directions for each orientation. The superficial neurons had a larger response to the null direction indicating reduced direction selectivity compared with the deeper neurons (Fig. 6A). The DMI (see Materials and Methods) increased with depth, from $0.32 \pm 0.03$ in superficial layer $2 / 3$ to $0.54 \pm 0.04$ in layer $4\left(R^{2}=0.78, p<10^{-9}\right.$; Fig. $6 C$; Table 1). When we separated neurons by response amplitude, we found that the DMl increased with depth across all response groups and the effect of depth was more pronounced with stronger responding neurons (Fig. 6B,D; Table 1). In the strongest responding group, the DMI nearly tripled from 0.22 in superficial layer $2 / 3$ to 0.53 in layer 4 (Fig. 6D; Table 1).

\section{Discussion}

Our findings demonstrate that neuronal responses in mouse V1 strongly depend on cortical depth. The percentage of responsive neurons and the amplitude of the responses increase by a factor of 2 with imaging depth from upper layer $2 / 3$ into layer 4 . By specifically considering the effect of cortical depth independent from changes in responsiveness, we showed that deeper neurons are less orientation selective than superficial neurons, largely due to increased unspecific responses. On the contrary, direction selectivity increased with cortical depth. Depth dependent changes did not occur only at the border
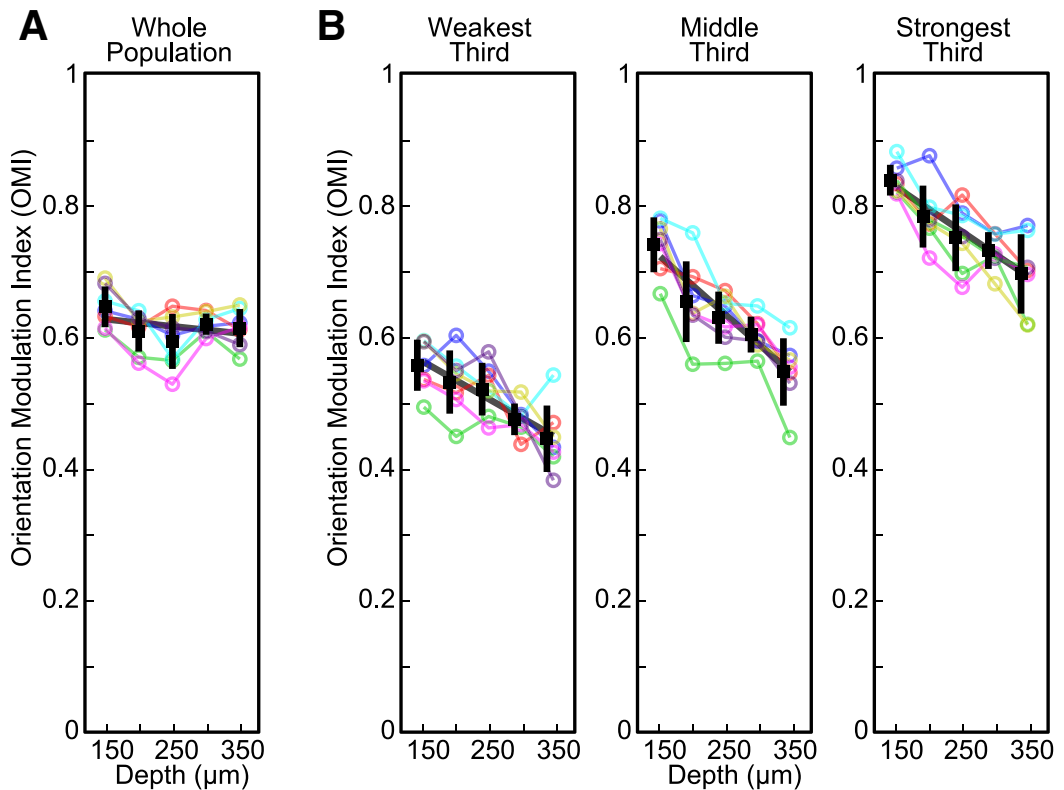

Figure 5. Cortical depth dependence of the OMI. $\boldsymbol{A}$, Average of OMI values for each mouse and imaging depth. $\boldsymbol{B}$, Average grouped by neuronal response amplitude. Conventions as in previous figures. 
A

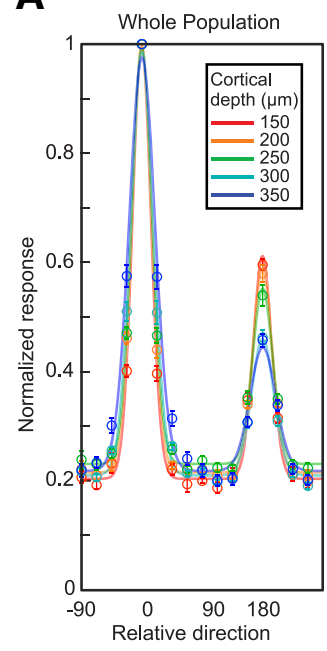

B

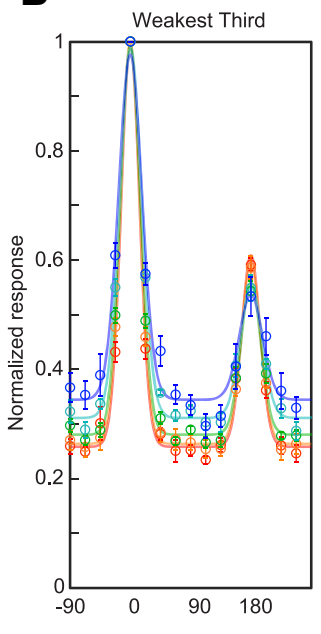

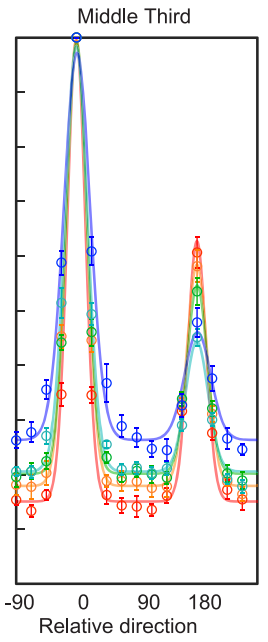

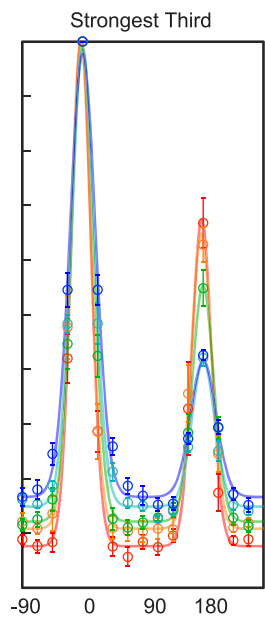

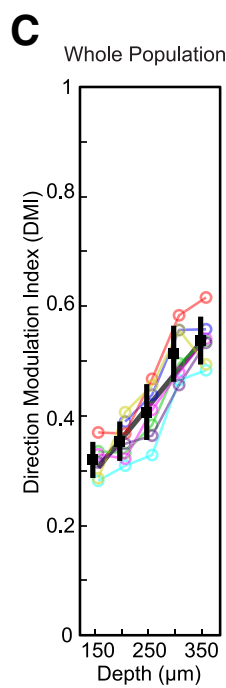

D

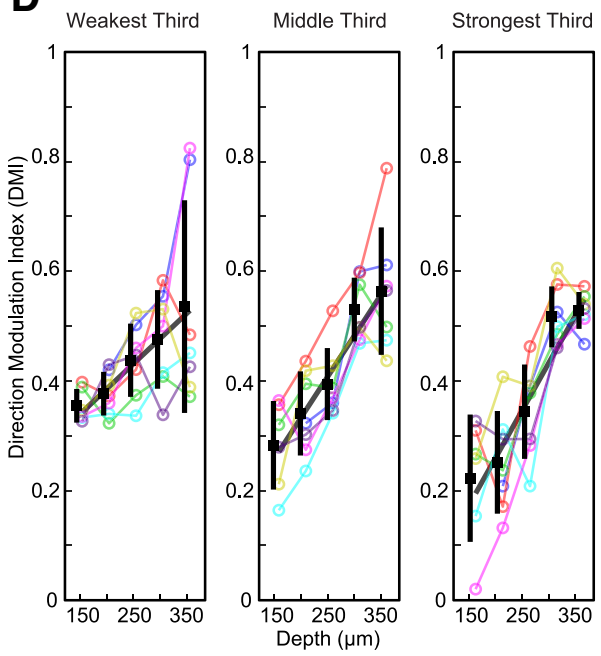

Figure 6. Cortical depth dependence of direction selectivity. A, Population average responses across all 16 directions at each depth were fit with a dual peak tuning curve (one peak for each of the two orthogonal directions; see Materials and Methods). $\boldsymbol{B}$, Same as $A$, but for populations grouped by response amplitude. $\boldsymbol{C}$, DMI computed from the fits. $\boldsymbol{D}$, Same as $\boldsymbol{C}$ but for neurons grouped by response amplitude. Conventions as in Figure 4.

between layer 3 and 4, but also across planes $(150,200$, and $250 \mu \mathrm{m}$ ) located within layer $2 / 3$.

\section{Determining the responsiveness of the visual cortex}

To accurately determine the percentage of responsive neurons in a region of cortex, one needs to monitor all the neurons in the tissue without bias. Electrophysiological recordings cannot achieve this since electrodes will only pick up neurons that fire action potentials and only in the region around the tip of the electrode. This limitation has led to the argument that most of V1 may be unresponsive to simple stimuli like oriented bars and gratings (Olshausen and Field, 2005; Shoham et al., 2006). In vivo two-photon microscopy bypasses this limitation since even silent neurons can be imaged. Recent two-photon imaging studies have demonstrated that nearly all of the neurons in cat and primate V1 respond to simple oriented stimuli (Kara and
Boyd, 2009; Nauhaus et al., 2012; Shen et al., 2012; Ikezoe et al., 2013; Li et al., 2017). Studies to date using mice have typically reported that only about half of mouse V1 neurons respond to oriented bars and gratings (Mrsic-Flogel et al., 2007; Sohya et al., 2007; Kerlin et al., 2010; Smith and Häusser, 2010; Bonin et al., 2011; Ebina et al., 2014; Ayzenshtat et al., 2016; Palagina et al., 2017). However, these studies did not report the fraction of responsive neurons at different cortical depths. Here, we show that deeper in layer $2 / 3$ and layer 4, nearly all the neurons in mouse V1 respond to oriented gratings.

Use of the synthetic dye OGB-AM was crucial to our study, because it labels all cells within a $300-$ to $400-\mu \mathrm{m}$ diameter volume, including those that are unresponsive to visual stimuli. In contrast, genetically encoded calcium indicators, e.g., GCaMP6, can have heterogeneous expression levels in a local region of tissue (Tian et al., 2009; Chen et al., 2013; Dana et al., 2014; Wilson et al., 2017), 
and their low baseline fluorescence can make the detection of inactive neurons difficult (Chen et al., 2013). Furthermore, over-expression of the indicators can impair neuronal health and reduce the ability to accurately detect activity. In the present study, we found that nearly all the cells in layer $2 / 3$ responded to local application of glutamate, indicating that they were healthy and additionally that we are able to detect their activity when present (Extended Data Fig. 1-2). This is consistent with previous studies, where the same protocol applied in the cat visual cortex (visualized dye injection at $\sim 200 \mu \mathrm{m}$ below the cortical surface; see Materials and Methods) yielded healthy responses in $>90 \%$ of imaged neurons, even in superficial layers (Kara and Boyd, 2009; Shen et al., 2012). It should be noted also that visually responsive and unresponsive cells were evenly spread throughout the imaged regions (Fig. 1; Extended Data Fig. 1-1) and that we did not observe clusters of unhealthy or saturated neurons even at the center of the injection. Taken together, these observations suggest that superficial neurons responded poorly to visual gratings not because they were unhealthy but rather because they perform a different function from deeper neurons.

Prior studies comparing the amplitude of responses between layer 2/3 and layer 4 of mouse V1 have typically reported few differences. One electrophysiological study found that in awake mice, evoked firing rates were higher in layer 4 than in layer 2/3 (Dadarlat and Stryker, 2017). However, this same group found no difference in mice anesthetized with urethane and chlorprothixene (Niell and Stryker, 2008). Other studies have found no difference in evoked firing between layer $2 / 3$ and layer 4 in awake mice (Durand et al., 2016) or mice anesthetized with urethane (Van den Bergh et al., 2010; Durand et al., 2016). In contrast, in mice anesthetized with the fentanyl cocktail, we find a dramatic increase in stimulus-evoked firing rates from layer 2/3 into layer 4.

\section{Orientation and direction selectivity across depth}

Although previous electrophysiological and imaging studies in mice have reported little variation in orientation selectivity with depth (Niell and Stryker, 2008; Ma et al., 2010; Van den Bergh et al., 2010; Durand et al., 2016; Kondo and Ohki, 2016; Sun et al., 2016; Yildirim et al., 2019), a trend toward greater orientation selectivity in more superficial layers was apparent across these studies. Our data show the same weak trend when all neurons in each depth plane are pooled together. However, when neurons were grouped by response strength, several interesting interactions between response amplitude, cortical depth, and orientation selectivity emerged. First, neurons with greater response amplitude, which are found in greater proportion deeper in layer 2/3 and layer 4 , tend to have greater selectivity. Second, for a given response strength, neurons deeper in the cortex tend to have less selectivity. In other words, superficial neuronal populations mostly consisted of weakly responsive, poorly orientation selective neurons, with a few strongly responsive, highly orientation selective neurons. Deeper in the cortex, neurons were more responsive, but were also less orientation selective than more superficial neurons with comparable response strength (Extended Data Fig. 3-1). As a result, orientation selectivity at the population level remained mostly constant across depth, although different circuit mechanisms may be involved. Additionally, we found that although superficial neurons are more selective for stimulus orientation, they are less selective for stimulus direction. Increased direction selectivity in layer 4 versus layer $2 / 3$ has been reported in one study (Sun et al., 2016) but others found no difference (Kondo and Ohki, 2016; Yildirim et al., 2019) or the opposite trend (Van den Bergh et al., 2010). Similar to orientation selectivity, grouping neurons by response strength showed that stronger responders were more direction selective and they showed greater increases in selectivity with depth than weaker responders. Interestingly, prior studies in nonrodent species have shown depth-dependent differences in orientation selectivity. In both macaques (Ringach et al., 2002) and tree shrews (Van Hooser et al., 2013) for instance, orientation selectivity was greater in superficial layer 2/3 than in deeper layer 2/3. However, in these earlier studies, layer 4 showed a similar level of selectivity to superficial layer $2 / 3$, unlike the continuous reduction in selectivity across cortical depth that we see in mice.

\section{Circuits for depth dependence of response properties}

One possible explanation for the increase in responsiveness with increasing depth in the mouse visual cortex may be the distribution of thalamic inputs. Genicular inputs are not as tightly constrained to layer 4 in mouse V1 (Nakamura et al., 2007; Ji et al., 2015; Kondo and Ohki, 2016; Sun et al., 2016) as they are in cats and primates (Gilbert and Wiesel, 1979; Friedlander and Martin, 1989). Rather, these inputs spread up into layer $2 / 3$, innervating the deeper part of layer $2 / 3$ quite strongly and becoming sparser more superficially. Thus, as the number of thalamic inputs increases with depth, the feed-forward neuronal drive could also increase, leading to a higher percentage of responding neurons and a greater response amplitude. This difference in thalamic inputs could also potentially explain the weakening of orientation selectivity with increasing depth. Because thalamic inputs to visual cortex have lower orientation selectivity than cortical neurons (Kondo and Ohki, 2016; Sun et al., 2016), the greater contribution of thalamic drive to neurons deeper in layer 3 and layer 4 could broaden the orientation tuning of these neurons relative to the more superficial neurons that receive a greater proportion of cortical inputs. It should be noted also that in the case of weakly responding neurons, orientation selectivity is inherently more difficult to measure due to the lower signal to noise ratio. This could have potentially reduced the relationship between depth and orientation selectivity we measured in this population. However, 
because the interaction between depth and selectivity was most pronounced in the strongest responding neurons, this rules out the possibility that the change in selectivity with depth is an artifact of analyzing noisy data.

In addition to the laminar distribution of thalamic boutons in visual cortex, the selectivity of the boutons themselves could also play a role in setting the selectivity for orientation and direction across layers. One study reported that geniculate boutons in layer 4 have lower orientation selectivity but greater direction selectivity than boutons in layer 2/3 (Sun et al., 2016). However, these differences are relatively small compared with the differences we see in the neurons of V1, likely reflecting intracortical connections that further amplify small differences seen in the boutons. For instance, neurons in layer 2/3 have been shown to be more likely to connect to neurons with the same preferred orientation, but there is little increase in connection probability for neurons with the same preferred direction (Ko et al., 2011). Thus, mouse V1 may adopt a coding strategy that favors maximizing orientation information at the expense of direction coding as information moves from layer 4 to layer $2 / 3$. One possible reason for this coding strategy might be the smaller number of neurons in V1 of mice relative to larger mammals. It could also be the case that in mouse V1, direction information is propagated to higher areas specialized for motion and spatial processing (Wang et al., 2011; Glickfeld and Olsen, 2017) by a relatively small dedicated set of neurons in layer $2 / 3$.

Another possibility is that the full screen gratings we used caused greater surround suppression in the superficial depths compared with layers 3 and 4 . Although past studies have reported that surround suppression is weaker in the infragranular layers than in layer 2/3 or layer 4 (Nienborg et al., 2013; Vaiceliunaite et al., 2013; Self et al., 2014; Plomp et al., 2019), none reported significant differences between layer $2 / 3$ and layer 4 or between superficial and deeper layer 2/3 (but see Van den Bergh et al., 2010).

\section{Implications for cortical coding}

Although weaker thalamic drive may explain the smaller percentage of responding neurons in superficial layer $2 / 3$, there is still the question of what stimuli might activate the silent half of the neurons. Previous studies have found neurons in mouse $\mathrm{V} 1$ that are unresponsive to single gratings but do respond to two overlapping gratings (Juavinett and Callaway, 2015; Muir et al., 2017; Palagina et al., 2017) or to contrast-noise stimuli (Gandhi et al., 2008; Niell and Stryker, 2008). Additionally, inputs to V1 from other sensory domains, which are essentially nonexistent in species like cat and primate, are prevalent in the mouse (Meredith and Lomber, 2017) and so some of the silent neurons may be selective for multisensory inputs. Locomotion has been shown to dramatically increase firing rates of neurons in mouse V1 (Niell and Stryker, 2010). Although it is not clear if locomotion increased the percentage of responsive neurons, it is likely that the increase in response amplitude across the population would lead to more neurons appearing significantly responsive. Neurons have also been found in mouse V1 that respond to stimuli in the ultra-violet range but not in the visible spectrum (Tan et al., 2015) which again may account for some of the silent neurons we see here.

The depth dependence of stimulus selectivity we have found may have important implications for how information is encoded in mouse visual cortex. Theories of sparse coding have proposed that neurons in higher areas respond more sparsely than neurons in lower areas because they become selective for increasingly complex stimulus features (Barlow, 1972; Olshausen and Field, 2004). Because the mouse visual system is simpler than that of species like cats and primates, functions typically performed by higher areas in those species may be delegated to V1 in the mouse (Niell and Stryker, 2010; Gavornik and Bear, 2014; Laramée and Boire, 2015). For instance, neurons in mouse $\mathrm{V} 1$ have been shown to be selective to the pattern motion of a plaid stimulus and not just the motion of the individual components (Muir et al., 2015; Palagina et al., 2017) - a property generally associated with higher visual areas in cats and primates (Gizzi et al., 1990; Albright and Stoner, 1995). Additionally, a recent study has shown that many neurons in mouse V1 are more strongly driven by complex stimuli with features such as corners, curves and textures than by the traditional gabortype stimuli that are commonly thought to match the receptive field structure of V1 neurons (Walker et al., 2019). So perhaps the unresponsive neurons we see in superficial layer 2/3 would respond to more complex stimuli that would drive neurons in higher areas of other species.

Functional properties may vary across cells located at different depths within layer 2/3 in other sensory systems as well. Studies in the somatosensory and auditory cortices of mice have described differences in layer 2 and layer 3 in terms of their response properties as well as in their neuronal cell types and connectivity (Bureau et al., 2006; Winkowski and Kanold, 2013; Staiger et al., 2015; Meng et al., 2017). This suggests that there may be a common principle of systematic differences between layer 2 and layer 3 across the primary sensory cortices in mice and that the common practice of lumping these layers together may be problematic in certain cases. It is also possible that the difference in information encoded by layers 2 and 3 may be generalizable to other species. A recent study in macaque $\mathrm{V} 1$ reported that, although nearly all neurons in superficial $L 2 / 3$ responded to oriented bars, many of them displayed much stronger responses to more complex stimuli (Tang et al., 2018). Thus, the greater sensitivity of superficial neurons to complex stimuli may be a general property of layer 2/3 across species. In order to determine the coding strategies of the neocortex, it is critical that future studies account for the laminar location and the depth within laminae of neurons when analyzing response properties. 
No. of cells

Population average

Population total

Responding, \%

Mouse 1

Mouse 2

Mouse 3

Mouse 4

Mouse 5

Mouse 6

Mouse 7

Population average

$\Delta F / F, \%$

Population average

Selective of responding, \%

Population average

No. of cells (responsive)

Weak responders

Moderate responders

Strong responders

No. of cells (selective)

Weak responders

Moderate responders

OS

Strong responders

Weak responders

Moderate responders

Strong responders

Population average

$\mathrm{OM}$

Weak responders

Moderate responders

Strong responders

Population average

Tuning width, bandwidth degrees

Weak responders

Moderate responders

Strong responders

Population average

Baseline response level, \% max resp

Weak responders

Moderate responders

Strong responders

Population average

DMI

Weak responders

Moderate responders

Strong responders

Population average

Responding, \%; $p \leq 0.001$

Population average

Responding, $\% ; \Delta F / F \geq 5 \%$

Population average

Uncorrected data, tuning width

Weak responders

Moderate responders

Strong responders

Population average $\begin{array}{rrrrr}150 \mu \mathrm{m} & 200 \mu \mathrm{m} & 250 \mu \mathrm{m} & 300 \mu \mathrm{m} & 350 \mu \mathrm{m} \\ & & & & \\ 81 \pm 49 & 176 \pm 36 & 179 \pm 31 & 186 \pm 42 & 237 \pm 68\end{array}$

$\begin{array}{lllll}1269 & 1233 & 1256 & 1301 & 1661\end{array}$

$\begin{array}{lllllll}27 & 55 & 77 & 84 & 80 & 0.80 & 0.0386 \\ 56 & 66 & 83 & 86 & 93 & 0.94 & 0.0059 \\ 52 & 72 & 92 & 93 & 94 & 0.82 & 0.0339 \\ 30 & 55 & 74 & 76 & 79 & 0.83 & 0.0311 \\ 38 & 58 & 67 & 85 & 91 & 0.97 & 0.0020 \\ 59 & 77 & 83 & 88 & 95 & 0.91 & 0.0106 \\ 60 & 73 & 91 & 91 & 92 & 0.80 & 0.0053 \\ 46 \pm 14 & 65 \pm 9 & 81 \pm 9 & 86 \pm 6 & 89 \pm 7 & 0.70 & 4.88 \mathrm{E}-10\end{array}$

$15.5 \pm 2.2 \quad 16.4 \pm 2.6 \quad 17.1 \pm 2.6 \quad 23.1 \pm 2.4 \quad 28.9 \pm 4.7 \quad 0.66 \quad 2.68 \mathrm{E}-09$

$\begin{array}{lllllll}79 \pm 6 & 78 \pm 4 & 76 \pm 4 & 78 \pm 5 & 73 \pm 7 & 0.10 & 0.07\end{array}$

$\begin{array}{lllll}317 & 393 & 481 & 301 & 180\end{array}$

$\begin{array}{lllll}182 & 285 & 370 & 362 & 474\end{array}$

$\begin{array}{lllll}78 & 125 & 170 & 462 & 840\end{array}$

$\begin{array}{lllll}249 & 316 & 368 & 222 & 122\end{array}$

$\begin{array}{lllll}151 & 216 & 287 & 291 & 332\end{array}$

$\begin{array}{lllll}62 & 92 & 124 & 363 & 638\end{array}$

$0.27 \pm 0.050 .25 \pm 0.030 .25 \pm 0.020 .22 \pm 0.010 .21 \pm 0.030 .41 \quad 3.60 \mathrm{E}-05$

$0.44 \pm 0.070 .36 \pm 0.050 .34 \pm 0.03 \quad 0.31 \pm 0.02 \quad 0.25 \pm 0.03 \quad 0.67 \quad 1.55 \mathrm{E}-09$

$0.59 \pm 0.07 \quad 0.52 \pm 0.040 .46 \pm 0.05 \quad 0.43 \pm 0.03 \quad 0.39 \pm 0.050 .69 \quad 7.95 \mathrm{E}-10$

$0.36 \pm 0.050 .33 \pm 0.02 \quad 0.31 \pm 0.02 \quad 0.33 \pm 0.02 \quad 0.32 \pm 0.02 \quad 0.12 \quad 0.0377$

$0.56 \pm 0.040 .53 \pm 0.050 .52 \pm 0.040 .48 \pm 0.02 \quad 0.45 \pm 0.050 .51 \quad 1.57 \mathrm{E}-06$

$0.74 \pm 0.040 .66 \pm 0.060 .63 \pm 0.040 .61 \pm 0.03 \quad 0.55 \pm 0.050 .65 \quad 4.12 \mathrm{E}-09$

$0.84 \pm 0.02 \quad 0.79 \pm 0.050 .75 \pm 0.050 .73 \pm 0.03 \quad 0.70 \pm 0.06 \quad 0.57 \quad 1.94 \mathrm{E}-07$

$0.64 \pm 0.030 .61 \pm 0.030 .60 \pm 0.040 .62 \pm 0.020 .62 \pm 0.03 \quad 0.05 \quad 0.1838$

$\begin{array}{lllllll}32.5 \pm 2 & 32.6 \pm 3 & 35.6 \pm 3 & 37.1 \pm 5 & 40.2 \pm 6 & 0.35 & 0.0002 \\ 32.0 \pm 2 & 35.6 \pm 2 & 35.5 \pm 3 & 38.6 \pm 4 & 43.4 \pm 4 & 0.59 & 9.72 \mathrm{E}-08 \\ 33.1 \pm 2 & 34.9 \pm 3 & 37.5 \pm 3 & 38.8 \pm 5 & 42.5 \pm 5 & 0.43 & 2.60 \mathrm{E}-05 \\ 32.4 \pm 0.7 & 34.0 \pm 2 & 35.5 \pm 2 & 38.2 \pm 4 & 42.6 \pm 4 & 0.62 & 3.99 \mathrm{E}-08 \\ & & & & & & \\ 23 \pm 3 & 27 \pm 5 & 29 \pm 3 & 31 \pm 2 & 34 \pm 4 & 0.53 & 1.18 \mathrm{E}-06 \\ 12 \pm 3 & 17 \pm 5 & 21 \pm 4 & 23 \pm 4 & 29 \pm 6 & 0.61 & 5.96 \mathrm{E}-08 \\ 6 \pm 3 & 9 \pm 4 & 11 \pm 3 & 17 \pm 2 & 19 \pm 5 & 0.66 & 4.39 \mathrm{E}-09 \\ 18 \pm 2 & 21 \pm 3 & 24 \pm 3 & 23 \pm 2 & 24 \pm 4 & 0.28 & 0.0012\end{array}$

$0.35 \pm 0.030 .38 \pm 0.040 .44 \pm 0.07 \quad 0.48 \pm 0.090 .54 \pm 0.190 .31 \quad 6.47 \mathrm{E}-04$ $0.28 \pm 0.080 .34 \pm 0.08 \quad 0.39 \pm 0.07 \quad 0.53 \pm 0.06 \quad 0.56 \pm 0.12 \quad 0.64 \quad 1.26 \mathrm{E}-08$

$0.22 \pm 0.120 .25 \pm 0.090 .34 \pm 0.090 .52 \pm 0.06 \quad 0.53 \pm 0.03 \quad 0.69 \quad 1.22 \mathrm{E}-09$

$0.32 \pm 0.030 .35 \pm 0.040 .41 \pm 0.050 .51 \pm 0.05 \quad 0.54 \pm 0.040 .78 \quad 4.47 \mathrm{E}-12$

$\begin{array}{lllllll}38 \pm 13 & 57 \pm 9 & 73 \pm 11 & 81 \pm 8 & 85 \pm 8 & 0.73 & 8.59 \mathrm{E}-11 \\ 57 \pm 16 & 79 \pm 11 & 88 \pm 6 & 90 \pm 4 & 93 \pm 6 & 0.55 & 3.34 \mathrm{E}-07 \\ & & & & & & \\ 30.7 \pm 2 & 31.9 \pm 3 & 34.7 \pm 3 & 35.0 \pm 4 & 36.2 \pm 4 & 0.27 & 0.0016 \\ 32.1 \pm 2 & 35.0 \pm 3 & 34.5 \pm 2 & 38.2 \pm 4 & 41.2 \pm 4 & 0.52 & 1.58 \mathrm{E}-06 \\ 32.9 \pm 3 & 34.7 \pm 3 & 37.3 \pm 3 & 38.0 \pm 5 & 42.0 \pm 5 & 0.41 & 4.31 \mathrm{E}-05 \\ 31.4 \pm 0.9 & 33.5 \pm 2 & 34.7 \pm 1 & 37.3 \pm 4 & 41.1 \pm 4 & 0.60 & 8.77 \mathrm{E}-08\end{array}$

0.0349

4.60E-05

0.0021

7.36E-06

0.0016

66E-07

1.22E-04

2.32E-07

1.96E-05

0.0500

0.0075

2.33E-06

1.60E-03

2.11E-06

1.53E-04

8.67E-06

8.74E-07

0.0054

0.0234

1.29E-06

2.70E-08

2.97E-10

(Continued) 


\begin{tabular}{|c|c|c|c|c|c|c|c|c|}
\hline $\begin{array}{l}\text { Uncorrected data, baseli } \\
\text { level }\end{array}$ & $150 \mu \mathrm{m}$ & $200 \mu \mathrm{m}$ & $250 \mu \mathrm{m}$ & $300 \mu \mathrm{m}$ & $350 \mu \mathrm{m}$ & $\mathbf{R}^{2}$ & $\begin{array}{c}P \\
\text { (linear } \\
\text { regression) }\end{array}$ & $\begin{array}{c}P \text { (ANOVA, } \\
\text { Depth } \\
\text { factor) }\end{array}$ \\
\hline Weak responders & $16 \pm 4$ & $21 \pm 6$ & $24 \pm 4$ & $24 \pm 4$ & $18 \pm 4$ & 0.02 & 0.39 & 0.0127 \\
\hline Moderate responders & $10 \pm 3$ & $17 \pm 6$ & $19 \pm 6$ & $21 \pm 4$ & $27 \pm 7$ & 0.53 & $9.11 \mathrm{E}-07$ & $5.25 \mathrm{E}-05$ \\
\hline Strong responders & $4 \pm 3$ & $8 \pm 4$ & $12 \pm 3$ & $15 \pm 2$ & $19 \pm 6$ & 0.67 & 2.92E-09 & $9.74 \mathrm{E}-07$ \\
\hline
\end{tabular}

For the percent responding, data for individual mice are shown in addition to the population average. The columns to the right of the depth columns give the $\mathrm{R}^{2}$ and $P$ values for linear regression on the data and the $P$ value for one-way analysis of variance with depth as the factor where applicable.

\section{References}

Adesnik H, Bruns W, Taniguchi H, Huang ZJ, Scanziani M (2012) A neural circuit for spatial summation in visual cortex. Nature 490:226-231.

Albright TD, Stoner GR (1995) Visual motion perception. Proc Natl Acad Sci USA 92:2433-2440.

Ayzenshtat I, Jackson J, Yuste R (2016) Orientation tuning depends on spatial frequency in mouse visual cortex. eNeuro 3:ENEURO. 0217-16.2016.

Barlow HB (1972) Single units and sensation: a neuron doctrine for perceptual psychology? Perception 1:371-394.

Bock DD, Lee W-C, Kerlin AM, Andermann ML, Hood G, Wetzel AW, Yurgenson S, Soucy ER, Kim HS, Reid RC (2011) Network anatomy and in vivo physiology of visual cortical neurons. Nature 471:177-182.

Bonin V, Histed MH, Yurgenson S, Reid RC (2011) Local diversity and fine-scale organization of receptive fields in mouse visual cortex. J Neurosci 31:18506-18521.

Bopp R, Maçarico da Costa N, Kampa BM, Martin KAC, Roth MM (2014) Pyramidal cells make specific connections onto smooth (GABAergic) neurons in mouse visual cortex. PLoS Biol 12: e1001932.

Bureau I, von Saint Paul F, Svoboda K (2006) Interdigitated paralemniscal and lemniscal pathways in the mouse barrel cortex. PLoS Biol 4:e382.

Chen TW, Wardill TJ, Sun Y, Pulver SR, Renninger SL, Baohan A, Schreiter ER, Kerr RA, Orger MB, Jayaraman V, Looger LL, Svoboda K, Kim DS (2013) Ultrasensitive fluorescent proteins for imaging neuronal activity. Nature 499:295-300.

D'Souza RD, Burkhalter A (2017) A laminar organization for selective cortico-cortical communication. Front Neuroanat 11:71.

Dadarlat MC, Stryker MP (2017) Locomotion enhances neural encoding of visual stimuli in mouse V1. J Neurosci 37:3764-3775.

Dana H, Chen T-W, Hu A, Shields BC, Guo C, Looger LL, Kim DS, Svoboda K (2014) Thy1-GCaMP6 transgenic mice for neuronal population imaging in vivo. PLoS One 9:e108697.

Douglas RJ, Martin KA (1991) A functional microcircuit for cat visual cortex. J Physiol 440:735-769.

Durand S, lyer R, Mizuseki K, De Vries S, Mihalas S, Reid RC (2016) A comparison of visual response properties in the lateral geniculate nucleus and primary visual cortex of awake and anesthetized mice. J Neurosci 36:12144-12156.

Ebina T, Sohya K, Imayoshi I, Yin ST, Kimura R, Yanagawa Y, Kameda H, Hioki H, Kaneko T, Tsumoto T (2014) 3D clustering of GABAergic neurons enhances inhibitory actions on excitatory neurons in the mouse visual cortex. Cell Rep 9:1896-1908.

Fahey PG, Muhammad T, Smith C, Froudarakis E, Cobos E, Fu J, Walker EY, Yatsenko D, Sinz FH, Reimer J, Tolias AS (2019) A global map of orientation tuning in mouse visual cortex. bioRxiv. doi: 10.1101/745323.
Friedlander MJ, Martin KA (1989) Development of Y-axon innervation of cortical area 18 in the cat. J Physiol 416:183-213.

Gandhi SP, Yanagawa Y, Stryker MP (2008) Delayed plasticity of inhibitory neurons in developing visual cortex. Proc Natl Acad Sci USA 105:16797-16802.

Gavornik JP, Bear MF (2014) Higher brain functions served by the lowly rodent primary visual cortex. Learn Mem 21:527-533.

Gilbert CD, Wiesel TN (1979) Morphology and intracortical projections of functionally characterised neurones in the cat visual cortex. Nature 280:120-125.

Gizzi MS, Katz E, Schumer RA, Movshon JA (1990) Selectivity for orientation and direction of motion of single neurons in cat striate and extrastriate visual cortex. J Neurophysiol 63:1529-1543.

Glickfeld LL, Olsen SR (2017) Higher-order areas of the mouse visual cortex. Annu Rev Vis Sci 3:251-273.

Ikezoe K, Mori Y, Kitamura K, Tamura H, Fujita I (2013) Relationship between the local structure of orientation map and the strength of orientation tuning of neurons in monkey V1: a 2-photon calcium imaging study. J Neurosci 33:16818-16827.

Ji W, Gămănuţ R, Bista P, D’Souza RD, Wang Q, Burkhalter A (2015) Modularity in the organization of mouse primary visual cortex. Neuron 87:632-643.

Juavinett AL, Callaway EM (2015) Pattern and component motion responses in mouse visual cortical areas. Curr Biol 25:1759-1764.

Kara P, Boyd JD (2009) A micro-architecture for binocular disparity and ocular dominance in visual cortex. Nature 458:627-631.

Kerlin AM, Andermann ML, Berezovskii VK, Reid RC (2010) Broadly tuned response properties of diverse inhibitory neuron subtypes in mouse visual cortex. Neuron 67:858-871.

Ko H, Hofer SB, Pichler B, Buchanan KA, Sjöström PJ, Mrsic-Flogel TD (2011) Functional specificity of local synaptic connections in neocortical networks. Nature 473:87-91.

Kondo S, Ohki K (2016) Laminar differences in the orientation selectivity of geniculate afferents in mouse primary visual cortex. Nat Neurosci 19:316-319.

Laramée ME, Boire D (2015) Visual cortical areas of the mouse: comparison of parcellation and network structure with primates. Front Neural Circuits 8:149.

Lee SH, Kwan AC, Zhang S, Phoumthipphavong V, Flannery JG, Masmanidis SC, Taniguchi H, Huang ZJ, Zhang F, Boyden ES, Deisseroth K, Dan Y (2012) Activation of specific interneurons improves $\mathrm{V} 1$ feature selectivity and visual perception. Nature 488:379-383.

Li M, Liu F, Jiang H, Lee TS, Tang S (2017) Long-term two-photon imaging in awake macaque monkey. Neuron 93:1049-1057.

Luo L, Callaway EM, Svoboda K (2008) Genetic dissection of neural circuits. Neuron 57:634-660.

Ma Wp, Liu Bh, Li Yt, Josh Huang Z, Zhang LI, Tao HW (2010) Visual representations by cortical somatostatin inhibitory neurons-selective but with weak and delayed responses. J Neurosci 30:1437114379. 
Mazurek M, Kager M, Van Hooser SD (2014) Robust quantification of orientation selectivity and direction selectivity. Front Neural Circuits 8:92.

Meng X, Winkowski DE, Kao JPY, Kanold PO (2017) Sublaminar subdivision of mouse auditory cortex layer $2 / 3$ based on functional translaminar connections. J Neurosci 37:10200-10214.

Meredith MA, Lomber SG (2017) Species-dependent role of crossmodal connectivity among the primary sensory cortices. Hear Res 343:83-91.

Mrsic-Flogel TD, Hofer SB, Ohki K, Reid RC, Bonhoeffer T, Hübener M (2007) Homeostatic regulation of eye-specific responses in visual cortex during ocular dominance plasticity. Neuron 54:961-972.

Muir DR, Roth MM, Helmchen F, Kampa BM (2015) Model-based analysis of pattern motion processing in mouse primary visual cortex. Front Neural Circuits 9:38.

Muir DR, Molina-Luna P, Roth MM, Helmchen F, Kampa BM (2017) Specific excitatory connectivity for feature integration in mouse primary visual cortex. PLoS Comput Biol 13:e1005888.

Nakamura K, Watakabe A, Hioki H, Fujiyama F, Tanaka Y, Yamamori T, Kaneko T (2007) Transiently increased colocalization of vesicular glutamate transporters 1 and 2 at single axon terminals during postnatal development of mouse neocortex: a quantitative analysis with correlation coefficient. Eur J Neurosci 26:3054-3067.

Nauhaus I, Nielsen KJ, Disney AA, Callaway EM (2012) Orthogonal micro-organization of orientation and spatial frequency in primate primary visual cortex. Nat Neurosci 15:1683-1690.

Niell CM, Stryker MP (2008) Highly selective receptive fields in mouse visual cortex. J Neurosci 28:7520-7536.

Niell CM, Stryker MP (2010) Modulation of visual responses by behavioral state in mouse visual cortex. Neuron 65:472-479.

Nienborg H, Hasenstaub A, Nauhaus I, Taniguchi H, Josh Huang Z, Callaway EM (2013) Contrast dependence and differential contributions from somatostatin- and parvalbumin-expressing neurons to spatial integration in mouse V1. J Neurosci 33:11145-11154.

O'Herron P, Shen Z, Lu Z, Schramm A, Levy M, Kara P (2012) Targeted labeling of neurons in a specific functional micro-domain of the neocortex by combining intrinsic signal and two-photon imaging. J Vis Exp 70:e50025.

O'Herron P, Chhatbar PY, Levy M, Shen Z, Schramm AE, Lu Z, Kara $P$ (2016) Neural correlates of single-vessel haemodynamic responses in vivo. Nature 534:378-382.

Ohki K, Chung S, Ch'ng YH, Kara P, Reid RC (2005) Functional imaging with cellular resolution reveals precise micro-architecture in visual cortex. Nature 433:597-603.

Olshausen BA, Field DJ (2004) Sparse coding of sensory inputs. Curr Opin Neurobiol 14:481-487.

Olshausen BA, Field DJ (2005) How close are we to understanding V1? Neural Comput 17:1665-1699.

Palagina G, Meyer JF, Smirnakis SM (2017) Complex visual motion representation in mouse area V1. J Neurosci 37:164-183.

Plomp G, Larderet I, Fiorini M, Busse L (2019) Layer 3 dynamically coordinates columnar activity according to spatial context. J Neurosci 39:281-294.

Ringach DL, Shapley RM, Hawken MJ (2002) Orientation selectivity in macaque $\mathrm{V} 1$ : diversity and laminar dependence. J Neurosci 22:5639-5651.

Runyan CA, Schummers J, Van Wart A, Kuhlman SJ, Wilson NR, Huang ZJ, Sur M (2010) Response features of parvalbumin-expressing interneurons suggest precise roles for subtypes of inhibition in visual cortex. Neuron 67:847-857.

Scanziani M, Häusser M (2009) Electrophysiology in the age of light. Nature 461:930-939.

Self MW, Lorteije JAM, Vangeneugden J, van Beest EH, Grigore ME, Levelt CN, Alexander Heimel J, Roelfsema PR (2014) Orientationtuned surround suppression in mouse visual cortex. J Neurosci 34:9290-9304.
Shen Z, Lu Z, Chhatbar PY, O’Herron P, Kara P (2012) An artery-specific fluorescent dye for studying neurovascular coupling. Nat Methods 9:273-276.

Shoham S, O'Connor DH, Segev R (2006) How silent is the brain: is there a "dark matter" problem in neuroscience? J Comp Physiol A Neuroethol Sens Neural Behav Physiol 192:777-784.

Smith SL, Häusser M (2010) Parallel processing of visual space by neighboring neurons in mouse visual cortex. Nat Neurosci 13:1144-1149.

Sohya K, Kameyama K, Yanagawa Y, Obata K, Tsumoto T (2007) GABAergic neurons are less selective to stimulus orientation than excitatory neurons in layer II/III of visual cortex, as revealed by in vivo functional $\mathrm{Ca} 2+$ imaging in transgenic mice. J Neurosci 27:2145-2149.

Staiger JF, Bojak I, Miceli S, Schubert D (2015) A gradual depth-dependent change in connectivity features of supragranular pyramidal cells in rat barrel cortex. Brain Struct Funct 220:1317-1337.

Sun W, Tan Z, Mensh BD, Ji N (2016) Thalamus provides layer 4 of primary visual cortex with orientation- and direction-tuned inputs. Nat Neurosci 19:308-315.

Swindale NV (1998) Orientation tuning curves: empirical description and estimation of parameters. Biol Cybern 78:45-56.

Tan Z, Sun W, Chen TW, Kim D, Ji N (2015) Neuronal representation of ultraviolet visual stimuli in mouse primary visual cortex. Sci Rep $5: 12597$.

Tang S, Lee TS, Li M, Zhang Y, Xu Y, Liu F, Teo B, Jiang H (2018) Complex pattern selectivity in macaque primary visual cortex revealed by large-scale two-photon imaging. Curr Biol 28:38-48.

Tian L, Hires SA, Mao T, Huber D, Chiappe ME, Chalasani SH, Petreanu L, Akerboom J, McKinney SA, Schreiter ER, Bargmann Cl, Jayaraman V, Svoboda K, Looger LL (2009) Imaging neural activity in worms, flies and mice with improved GCaMP calcium indicators. Nat Methods 6:875-881.

Vaiceliunaite A, Erisken S, Franzen F, Katzner S, Busse L (2013) Spatial integration in mouse primary visual cortex. J Neurophysiol 110:964-972.

Van den Bergh G, Zhang B, Arckens L, Chino YM (2010) Receptivefield properties of $\mathrm{V} 1$ and $\mathrm{V} 2$ neurons in mice and macaque monkeys. J Comp Neurol 518:2051-2070.

Van Hooser SD, Li Y, Christensson M, Smith GB, White LE, Fitzpatrick D (2012) Initial neighborhood biases and the quality of motion stimulation jointly influence the rapid emergence of direction preference in visual cortex. J Neurosci 32:7258-7266.

Van Hooser SD, Roy A, Rhodes HJ, Culp JH, Fitzpatrick D (2013) Transformation of receptive field properties from lateral geniculate nucleus to superficial V1 in the tree shrew. J Neurosci 33:1149411505.

Walker EY, Sinz FH, Cobos E, Muhammad T, Froudarakis E, Fahey PG, Ecker AS, Reimer J, Pitkow X, Tolias AS (2019) Inception loops discover what excites neurons most using deep predictive models. Nat Neurosci 22:2060-2065.

Wang Q, Gao E, Burkhalter A (2011) Gateways of ventral and dorsal streams in mouse visual cortex. J Neurosci 31:1905-1918.

Wilson DE, Smith GB, Jacob AL, Walker T, Dimidschstein J, Fishell G, Fitzpatrick D (2017) GABAergic neurons in ferret visual cortex participate in functionally specific networks. Neuron 93:10581065.

Winkowski DE, Kanold PO (2013) Laminar transformation of frequency organization in auditory cortex. J Neurosci 33:1498-1508.

Yildirim M, Sugihara H, So PTC, Sur M (2019) Functional imaging of visual cortical layers and subplate in awake mice with optimized three-photon microscopy. Nat Commun 10:177.

Zhao S, Ting JT, Atallah HE, Qiu L, Tan J, Gloss B, Augustine GJ, Deisseroth K, Luo M, Graybiel AM, Feng G (2011) Cell type-specific channelrhodopsin-2 transgenic mice for optogenetic dissection of neural circuitry function. Nat Methods 8:745-752. 